CASA, Vol.9 n.1, julho de 2011

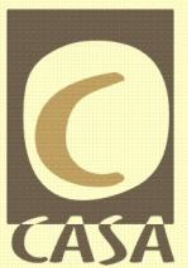

Cadernos de Semiótica Aplicada

Vol. 9.n.1, julho de 2011

Publicação SEMESTRAL

ISSN: $1679-3404$

\title{
O CORPO ENUNCIADO E SUAS METAMORFOSES: OPERAÇÕES ENUNCIATIVAS EM ANÚNCIOS CLASSIFICADOS DE SERVIÇO DE $\mathrm{SEXO}^{1}$
}

\section{THE ENUNCIATIVE BODY AND ITS METAMORPHOSES: ENUNCIATIVE OPERATIONS IN NEWSPAPER SEX ADS}

\author{
Ricardo Lopes Leite ${ }^{2}$ \\ UFC - Universidade Federal do Ceará
}

\begin{abstract}
RESUMO: Este artigo examina os diferentes modos de apresentação do corpo em anúncios classificados de serviço de sexo. Com a análise desses textos, quer-se demonstrar que esses simulacros do corpo são efeitos de sentido gerados, sobretudo, pelas operações enunciativas de debreagem e embreagem, ambas subcategorizadas em enunciva e enunciativa, bem como pelos arranjos figurativos, entendidos como funtivos de posições enunciativas de observação. Com o propósito de persuadir o leitor, o jogo enunciativo apresenta-lhe o "corpo-objeto-de-consumo" sob diferentes perspectivas: ora objetiva, ora subjetiva, ou objetiva e subjetiva simultaneamente.
\end{abstract}

PALAVRAS-CHAVE: corpo; operações enunciativas; anúncios classificados de serviço de sexo.

ABSTRACT: This paper examines different ways of introducing the body within newspaper sex ads. From analyzing such texts, the study demonstrates that these body simulacrums are meaningful effects mostly generated by shifting out and shifting in enunciative operations, both subcategorized as enuncive and enunciative, as well as by their figurative arrangements, seen as functive for enunciative observation positions. In order to persuade the reader, the enunciative game introduces himlher the "consummation object body" under different perspectives: either subjective or objective, and at times both simultaneously.

KEYWORDS: body; enunciative operations; newspaper sex ads.

\section{Introdução}

\footnotetext{
${ }^{1} \mathrm{O}$ interesse pelo tema do nosso artigo deve-se especialmente à leitura da obra Figurativização e Metamorfose: $o$ mito de Narciso, do professor Ignácio Assis Silva, e de dois artigos (cf. DUARTE, 1996; LANDOWSKI, 1996) da coletânea Corpo e sentido: a escuta do sensível, por ele organizada.

2 Professor do Departamento de Letras Vernáculas e do Programa de Pós-Graduação em Linguística da Universidade Federal do Ceará. Coordenador do Grupo de Estudos Semióticos da Universidade Federal do Ceará (SEMIOCE).
} 
O corpo ocupa lugar central nos estudos semióticos atuais, sobretudo na vertente tensiva da semiótica francesa, na medida em que sua postulação constitui uma das condições sine quibus non seria possível inserir o contínuo e as tensões não discretizáveis em seus domínios de investigação. Sem esta postulação, não se lograria atribuir o destaque necessário à percepção e à enunciação na geração do sentido.

O interesse da semiótica pelo corpo é, na verdade, um interesse pelo(s) simulacro(s) do corpo. Sem compromisso com ontologias, mas prudentemente apoiada em uma fenomenologia, a semiótica se abstém de falar do corpo como coisa real, pois o toma como operador teórico sensível às modulações do meio, organizadas interna e externamente em formas semióticas. Assim sendo, o corpo articula dois regimes de apreensão da realidade, o inteligível e o sensível, simulados no discurso pela função sígnica. Sua existência somente é possível com e pelo ato enunciativo, na medida em que o eu-que-sente-e-percebe precisa ser deslocado do simples vivido (este, por sua vez, indizível) e reconhecido como eu-que-enuncia para que o universo de sentido lhe apareça.

Se enunciar é tornar as coisas presentes por meio da linguagem, conforme assevera Fontanille (2008), a enunciação impõe-se como ato fundador da significação, pois, mais que apontar para um sujeito empírico como origem do discurso, ela o cria. Isso equivale a dizer que o sujeito da enunciação se constrói no próprio ato de enunciar: embora nunca se mostre empiricamente, faz-se conhecer, ou se deixa flagrar indiretamente como imagem-fim reconstruída em um dado texto por aquele que o recebe por intermédio de marcas deixadas no discurso.

Do ponto de vista semiótico, a estrutura da enunciação comporta duas instâncias: a do enunciador e a do enunciatário, sendo o termo sujeito da enunciação o sincretismo dessas duas posições actanciais e não somente um sinônimo da posição de enunciador, como pode dar a entender o termo. A enunciação pode ser analisada por meio de duas operações correlatas: a debreagem e a embreagem, ambas subcategorizadas em enunciva e enunciativa. Em linhas gerais, essas operações são procedimentos de discursivização, mecanismos de instauração das categorias de pessoa, espaço e tempo no enunciado. Cada texto-objeto, por conseguinte, circunscrito numa configuração genérica, constrói para si, em função dessas operações enunciativas, os papéis de enunciador e enunciatário, ao mesmo tempo em que define o estatuto discursivo dos objetos textuais.

Neste artigo, elegemos alguns anúncios classificados de serviço de sexo para identificarmos os diferentes simulacros do corpo engendrados na cena textual pelo enunciador, com o fito de fornecer diferentes imagens ${ }^{3}$ do corpo-objeto-de-consumo para o enunciatário. Fundamentados em uma perspectiva de discurso em ato, supomos que os efeitos de sentido gerados nesses anúncios estão na dependência direta das operações de debreagem e embreagem, bem como da disposição figurativa do plano discursivo, resultantes de diferentes posições enunciativas perspectivadas pelo observador.

Se forem tomados como um conjunto enunciativo ou parte de uma totalidade discursiva, esses textos podem deixar-se apreender pelas recorrências do dizer, permitindonos examinar o modo como os simulacros do corpo são ali construídos.

\footnotetext{
${ }^{3}$ Esse termo é tomado aqui na acepção fornecida por Greimas e Courtés (2008, p. 254): "uma unidade de manifestação autossuficiente, como um todo de significação, capaz de ser submetido à análise". 
CASA, Vol.9 n.1, julho de 2011

\section{O corpo e o sujeito da enunciação}

Para a Semiótica Discursiva, a noção de corpo repousa em bases fenomenológicas. O termo remete principalmente à obra Fenomenologia da percepção, de Merleau-Ponty (1999), em que o filósofo francês propõe a aquisição do conhecimento pela percepção e pelo movimento, destacando o papel do que ele denomina "corpo próprio": uma entidade experiencial, em que o interno e o externo, o biológico e o fenomenológico se comunicam, sem oposições.

Esta definição, consoante Tatit (2007), permite a diluição da distância teórica entre sujeito e objeto, haja vista a experiência de percepção do corpo ser extensiva à experiência de percepção do mundo, o que resulta em aparente equivalência entre aquele e a própria unidade do ser, marcada por uma espécie de continuidade, por uma junção plena, na qual não se sabe, ao certo, onde termina o sujeito e começa o objeto. Do ponto de vista semiótico, todavia, essa equivalência é rompida, na medida em que, pelo ato enunciativo, corpo e mundo disjungem-se, a fim de que se estabeleça um campo de presença capaz de orientar e controlar o conjunto de grandezas convocadas em um dado discurso. No entanto, se, por um lado, essa cisão rompe a continuidade "corpo-mundo", por outro, instaura a busca pelo sentido.

Desse modo, a enunciação, vista como ato, funda-se naquilo que Greimas e Courtés (2008, p. 168) definem como "intencionalidade": uma visada, uma ação orientada "graças à qual o sujeito constrói o mundo enquanto objeto ao mesmo tempo em que constrói a si próprio". Em outros termos, ao enunciar, a instância do discurso enuncia sua própria posição, o que nada mais é do que "a posição que o sujeito da percepção atribui-se no mundo quando ele se põe a depreender seu sentido" (FONTANILLE, 2007, p. 43). O ato de enunciar consiste, por conseguinte, em organizar o espaço discursivo em torno de um centro sensível.

Convém ressaltar que não se trata de um simples ponto, um centro de referência para a dêixis, imune às modulações afetivas ou passionais do discurso, como apregoaria uma teoria formal da enunciação. Em uma semiótica do sensível, o corpo "será tratado como um invólucro, sensível às demandas e aos contatos vindos seja do exterior (sensações), seja do interior (emoções e afetos)", como bem acentua Fontanille (2007, p. 45). Trata-se, segundo esse autor, da primeira forma que o actante da enunciação assume, uma vez que, antes de ser identificado como um sujeito (eu), ele se instala como centro de referência sensível, reagindo à presença que o circunda. Por isso, as categorias da dêixis (o espaço, o tempo e o actante da enunciação) não constituem apenas formas linguísticas, uma vez que se associam, a princípio, a uma experiência perceptiva e afetiva de presença.

Fontanille e Zilberberg (2001) alertam para o perigo da redução do "eu" semiótico ao "eu" linguístico, já que aquele não se limita a um "eu identitário", revelando-se muito mais um "eu oscilatório", afetado e comovido pelos êxtases que o impactam. Vale citar o comentário abaixo, em que os autores esclarecem esse ponto de vista:

O 'eu' semiótico habita um espaço tensivo, ou seja, um espaço em cujo âmago a intensidade e a profundidade estão associadas, enquanto o sujeito se esforça, a exemplo de qualquer vivente, por tornar esse nicho habitável, isto é, por ajustar e regular as tensões, organizando as morfologias que o condicionam (FONTANILLE \& ZILBERBERG, 2001, p. 128).

Tendo em vista que o detalhamento dos conceitos relativos à tensividade foge aos propósitos deste artigo, basta-nos complementar o que foi dito no parágrafo anterior com a seguinte explicação de Zilberberg (2006, p. 169): 
(i) a tensividade é o lugar imaginário em que a intensidade - ou seja, os estados de alma, o sensível - e a extensidade - isto é, os estados de coisas, o inteligível - unem-se uma a outra; (ii) essa junção indefectível define um espaço tensivo de recepção para as grandezas que têm acesso ao campo de presença: pelo próprio fato de sua imersão nesse espaço, toda grandeza discursiva vê-se qualificada em termos de intensidade e extensidade.

Visto por esse prisma, o discurso passa a ser compreendido como um campo de presença instalado pelo próprio corpo, mas que ao mesmo tempo o comporta, cuja modulação perceptiva ora aproxima determinados conteúdos para o seu núcleo, ora afasta-os para sua periferia, o que resulta em diferentes profundidades ou níveis de apreensão dos objetos por ele visados. A fundamentação do sentido, por sua vez, vê-se redimensionada, pois as operações polarizadas de afirmação e negação do quadrado semiótico passam a ser consideradas em função do termo complexo ou, se preferirmos, das inflexões tônicas e átonas articuladas nos eixos de intensidade e extensidade.

Se a tomada de posição operada no e pelo ato enunciativo significa "construir versões sensíveis e inteligíveis do mundo", ou ainda, "criar perspectivas a partir das quais o vivido se apresenta sempre redimensionado pelo próprio ato enunciativo" (SARAIVA, 2008, p. 41), a análise semiótica passa a dever ser ancorada na enunciação, no discurso em ato. Ou seja, põe-se em foco o sujeito, e se concede primazia ao discurso como ato fundador daquele que, ao enunciá-lo, enuncia-se e se afirma.

Pouco importa, então, atestar a existência de um sujeito empírico, haja vista essa existência ser apenas pressuposta, sem jamais incidir sobre a análise textual. Vejamos a definição de Bertrand (2003, p. 82) acerca do sujeito do discurso:

[...] é uma posição pura e simples. Instância teórica de que nada se sabe no início, esse sujeito constrói pouco a pouco, ao longo do discurso, sua espessura semântica. Sua identidade resulta do conjunto de informações e das determinações de toda a ordem que lhe dizem respeito no texto.

O sujeito que se quer flagrar nos textos que analisaremos é, por conseguinte, aquele que se faz (re)conhecer como efeito de sentido: como simulacro linguístico de enunciações enunciadas.

\section{As operações enunciativas}

Greimas e Courtés (2008, p.166) definem a enunciação como "instância linguística, logicamente pressuposta pela própria existência do enunciado (que dela contém traços e marcas)". Este, por oposição àquela, pode ser definido como o estado que dela resulta, independente de suas dimensões sintagmáticas, e cujos elementos remetem com frequência à instância da enunciação; é o caso, por exemplo, dos pronomes pessoais e possessivos, bem como dos dêiticos espaciais e temporais.

Consoante os autores, a enunciação responde pela discursivização da língua, pois assegura a atualização das formas semióticas virtuais em estruturas realizadas sob a forma de discurso. $\mathrm{O}$ ato de linguagem aparece "por um lado, como uma fenda criadora do sujeito, do lugar e do tempo da enunciação e, por outro, da representação actancial, espacial e temporal do enunciado" (GREIMAS e COURTÉS, 2008, p. 111). 
Sem o propósito de esmiuçar as "astúcias da enunciação", pelo que remetemos o leitor à obra homônima de Fiorin $(2002)^{4}$, sumarizamos, a seguir, as operações enunciativas de debreagem, que se desmembra em enunciativa e enunciva, de embreagem (também subdividida em enunciativa e enunciva) e a instância enunciativa de observador, convocada mediante esses mecanismos breantes.

De acordo com Fiorin (2002, p. 43), a debreagem consiste, em um primeiro momento, "em disjungir do sujeito, do espaço e do tempo da enunciação e em projetar no enunciado um não eu, um não aqui e um não agora". Trata-se da projeção de categorias semânticas operadas pelo sujeito enunciante a fim de instalar o universo de sentido, já que o puro vivido não é comunicável. Mediante esse ato, inaugura-se o enunciado ao mesmo tempo em que, de maneira implícita, articula-se a própria instância da enunciação. Há dois tipos de debreagem: a enunciativa e a enunciva. A primeira instala no enunciado os actantes (eu/tu), o espaço (aqui) e o tempo (agora) da enunciação. A segunda instaura no enunciado os actantes (ele/eles), o espaço (algures) e o tempo (então) do enunciado.

Por meio das debreagens enunciativa e enunciva, obtêm-se no discurso dois grandes efeitos de sentido: a) de subjetividade, quando os simulacros do ego-hic-nunc enunciativos instalados no enunciado geram um efeito de aproximação, de apreciação de fatos; e b) de objetividade, quando o apagamento das marcas da enunciação no enunciado produzem um efeito de distanciamento, de imparcialidade. Uma vez que a instância da enunciação pode ser concebida como o sincretismo do eu-aqui-agora, teremos respectivamente uma debreagem actancial, espacial e temporal, tanto enunciativa quanto enunciva.

A debreagem actancial enunciativa instala no enunciado o simulacro do eu enunciador, a debreagem espacial enunciativa ordena o espaço do enunciado em função do aqui enunciativo e a debreagem enunciativa temporal instala no enunciado termos ordenados em relação ao agora da enunciação. A título de exemplificação, teríamos na frase "eu estive aqui ano passado" a coexistência dos três tipos de debreagem enunciativa, marcadas, respectivamente, pelo pronome pessoal, pelo dêitico espacial e pelo dêitico temporal.

As debreagens enuncivas actancial, espacial e temporal, por sua vez, instalam no enunciado seus actantes (ele, eles), seu espaço (algures) e seu tempo (então). Fiorin (2002, p. 45) fornece como exemplo da ocorrência dessas debreagens o seguinte trecho da obra Quincas Borba, de Machado de Assis:

Rubião fitava a enseada, - eram oito horas da manhã. Quem o visse, com os polegares metidos no cordão do chambre, à janela de uma grande casa de Botafogo, cuidaria que ele admirava aquele pedaço de água quieta (Grifos nossos).

Conforme podemos observar, o mecanismo de debreagem consiste em pluralizar a instância de discurso, a fim de que possa comportar, ainda que virtualmente, uma infinidade de espaços, tempos e atores.

Ao contrário da debreagem, que expulsa da instância da enunciação os termos categóricos (atores, tempo e espaço) do enunciado, a embreagem consiste em um:

\footnotetext{
${ }^{4}$ Fiorin, nessa obra, explora brilhantemente as inúmeras possibilidades e desdobramentos dos processos enunciativos, atribuindo-lhes subcategorizações (como é o caso, por exemplo, das debreagens internas), além de fornecer variados exemplos.
} 
[...] efeito de retorno à enunciação, produzido pela suspensão da oposição entre certos termos da categoria da pessoa e/ou do espaço, e/ou do tempo, bem como pela denegação da instância do enunciado (GREIMAS e COURTÉS, 2008, p. 159-160).

Com isso, produz-se a impressão de identificação entre as categorias de pessoa, espaço e tempo do enunciado e da enunciação. Temos uma embreagem actancial quando ocorre uma neutralização da categoria de pessoa (por exemplo, quando o próprio presidente da República diz "O presidente da República não mede esforços para preservar a democracia", há uma neutralização da oposição eu/ele). Na embreagem temporal temos a neutralização da categoria de tempo (por exemplo, quando neutralizamos a oposição entre pretérito perfeito e presente do indicativo em uma frase como "fui à festa ontem à noite e encontro Júlia, que não via há muito tempo"). Já na embreagem espacial, neutraliza-se a categoria de espaço (como exemplo, temos a utilização do verbo "vir", que remete ao espaço da enunciação: "Todos os reis responderam (...) que eles teriam muito prazer de vir ao Congresso").

Fiorin (2002) distingue ainda a embreagem enunciativa e a enunciva. $\mathrm{Na}$ primeira, o termo debreante é tanto enunciativo como enuncivo, mas o embreante é enunciativo. O autor fornece o seguinte exemplo: "Em Minas o futuro é agora", em que se nega a posterioridade com a concomitância enunciativa. Na segunda, o termo debreante pode ser enunciativo ou enuncivo, mas o termo embreante é necessariamente enuncivo. Ou seja, no caso de uma embreagem actancial, por exemplo, nega-se a subjetividade, pondo-se em relevo a terceira pessoa em detrimento da primeira.

É importante lembrar que todo ato embreante pressupõe uma debreagem, que lhe é logicamente anterior. Segundo Greimas e Courtés (2008, p. 160), "é impossível conceber a embreagem total; ela equivaleria a apagar toda marca do discurso, seria a volta ao 'inefável'”.

\section{O observador e a figurativização}

No que tange ao observador, o Dicionário de Semiótica, de Greimas e Courtés (2008, p. 347), assim o define: "será chamado de observador o sujeito cognitivo delegado pelo enunciador e por ele instalado, graças aos procedimentos de debreagem, no discurso enunciado, em que é encarregado de exercer o fazer receptivo e, eventualmente, o fazer interpretativo".

A essa definição podemos acrescer o comentário que consta no tomo II do dicionário, segundo o qual "o actante observador é um lugar preparado pelo enunciador para o enunciatário, e um dos mais importantes elementos do efeito de real" (GREIMAS; COURTÉS, 1986, p.156), ${ }^{5}$ bem como a opinião de Bertrand (2003), segundo a qual o observador é visto como a instância enunciativa capaz de simular o deslocamento do leitor para um lugar, ou posição de onde, ele, leitor, possa perceber determinados modos de apresentação ou perspectivas do objeto visado.

Apesar de o texto simular o deslocamento do observador para uma posição enunciativa, na qual possa exercer sua atividade perceptiva, Bertrand adverte que seu aparecimento depende da discursivização textual; pode, por exemplo, tanto ser induzido pela

\footnotetext{
5 "l'actant observateur est une place préparée par l'énonciateur pour l'énonciataire, et un élément majeur de l'effet de réel'. No tomo 2, ainda não traduzido para o português, o conceito de observador é refinado com comentários de Jacques Fontanille, François Rastier e Sorin Alexandrescu.
}

Disponível em: http://seer.fclar.unesp.br/casa 
disposição dos objetos no texto quanto explicitado por meio de predicados da percepção (perceber, ver, envolver com o olhar, explorar, examinar etc.).

A disposição e a sensibilização perceptiva dos objetos textuais permitem ao observador agenciar cognitivamente os pontos de vista que regulam os modos pelos quais o enunciado pode ser apreendido. Diante disso, o enunciador pode manipular o enunciatário, elegendo um determinado ponto de vista, e simulá-lo no discurso como sendo a sua própria posição de enunciação, ou, ainda, construir um único lugar de observação em que enunciador e enunciatário se encontrem sincretizados, como na aparente objetividade do discurso científico (cf. LEITE e SARAIVA, 2009).

Seguindo o mesmo raciocínio, Bertrand (2003) afirma que o modo de presença do observador implica a exploração de uma orientação discursiva, mediada pelas posições graduais de debreagem e embreagem enunciativas, quer se trate do discurso narrativo, descritivo ou argumentativo. No primeiro caso, o observador pode, por exemplo, dispor a estrutura narrativa sob a perspectiva do herói, deixando oculta a do antissujeito, que somente aparece em momentos de prova e sanção; no segundo caso, a ordem de apresentação dos elementos, bem como sua disposição espaciotemporal podem convocar conteúdos de ordem cognitiva ou passional que irão interferir na descrição; por fim, no terceiro caso, o observador aparece como um ponto de vista, a expressão de um juízo ou opinião, capaz de determinar o modo como o enunciador instala o discurso de outrem, com o propósito de refutá-lo ou de consolidar seu próprio discurso.

Do que foi exposto até o momento, é preciso, ainda, destacar o papel da figurativização nos processos enunciativos, visto que a adesão a um determinado discurso se apoia sobre valores figurativos advindos da percepção, que o discurso social transforma em valores axiológicos como, por exemplo, os estereótipos. Assumida dessa forma, a figurativização não se resume à representação mimética, mas diz respeito a um processo gradual, regulado, no discurso, pela iconização (que promove a semelhança com as figuras do mundo) e pela abstração (que delas se afasta).

Greimas (2002, p. 74) propõe a seguinte definição, que melhor sumariza o parágrafo acima: "a figuratividade não é uma simples ornamentação das coisas, ela é esta tela do parecer", uma espécie de "arena do sentido", a fachada mais concreta do discurso, que faz surgir na língua as imagens da experiência sensível do mundo, pondo-nos em contato com uma espécie de ilusão referencial.

Diante disso, é nosso objetivo averiguar, nos anúncios classificados de sexo selecionados, os simulacros do corpo construídos no discurso pelas operações enunciativas já citadas, bem como pelos arranjos das figuras do plano discursivo, resultantes de posições enunciativas de observação.

\section{As operações enunciativas e os simulacros do corpo em anúncios classificados de serviço de sexo ${ }^{6}$}

"Fazer ver também é fazer crer." (BERTRAND, 2003, p.155)

\footnotetext{
${ }^{6}$ Os anúncios analisados neste artigo foram selecionados da seção Social e lazer dos classificados do dia 10 de junho de 2010, do jornal Diário do Nordeste, de grande circulação na cidade de Fortaleza, Ceará. Lembramos que o termo anúncios classificados de serviço de sexo recebe outras denominações como classificados de sexo, anúncios classificados da seção acompanhantes etc., que, de modo algum, implicam descaracterização desse gênero discursivo.
} 
Os anúncios classificados constituem, do ponto de vista genérico, um tipo de texto descritivo, publicado em jornais (impressos ou online), cuja função sócio-comunicativa pode ser entendida como vender, alugar ou trocar produtos e serviços diversos. No caso particular dos anúncios classificados de serviço de sexo, o objeto/produto/serviço de consumo é o corpo. Na medida em que o que está em jogo não é o corpo real, mas sim os simulacros construídos no discurso, esses textos operam com diversas estratégias de persuasão para fazer o corpo enunciado parecer verdadeiro, para que prevaleça, em última instância, o fazer-fazer, próprio do discurso publicitário.

Em termos discursivos, são as operações enunciativas que respondem por esses efeitos de realidade ou de verdade presentes nesse tipo de texto, fazendo que surjam imagens do corpo ora objetivas ora subjetivas, ou objetivas e subjetivas ao mesmo tempo. Vejamos como isso pode ser examinado nos quatro anúncios apresentados a seguir: ${ }^{7}$

ARIANY. 31 anos, 1.65m, 63kg, p/ homens acima de 37 anos. Fone XXXXXXXX.

Do ponto de vista enunciativo, temos uma debreagem enunciva actancial, que instaura uma $3^{\text {a }}$ pessoa no enunciado (Ariany), que se enuncia pela dimensão do inteligível, da extensidade ( 31 anos, 1,65m, $63 \mathrm{~kg}$, p/ homens acima de 37 anos). Essa operação constitui, a nosso ver, uma estratégia do enunciador para agenciar a representação do "corpo enunciado" que se quer mostrar para o enunciatário. Com isso, obtém-se um efeito de objetividade por conta do apagamento das marcas da enunciação no enunciado, que se traduz, também, em um efeito de "distanciamento" da cena descritiva, que permite ao enunciatário visualizar o simulacro do corpo como figura para a apreensão objetiva.

Essa visualização não é, de modo algum, ingênua, pois se as figuras do discurso se apresentam dotadas de sentido, é porque implicam, de alguma maneira, o functivo obervador, sem o qual não há "ver" o objeto. Além do mais, como bem assinala Bertrand (2003, p. 125), "a partir do momento em que há discurso e representação, há sempre um observador que comanda sua disposição". Ora, se o observador, como já vimos, é o sujeito cognitivo delegado e instalado pelo enunciador via debreagem para simular, dentre outras coisas, o deslocamento do leitor para um lugar ou posição determinante para os modos de apreensão do objeto visado, então ele, observador, constitui-se como um dos dispositivos de manipulação dos quais pode o enunciador lançar mão com vistas ao fazer-fazer.

O sucesso da manipulação, todavia, depende tanto do ponto de vista do observador sobre a disposição das características físicas do corpo enunciado, quanto da avaliação cognitiva, por ele implementada, dos valores apresentados por triagem, que constroem a figura do corpo-mercadoria (31 anos, 1,65m, $63 \mathrm{~kg}$ ) e que pressupõem já um universo valorativo do qual participam enunciador e enunciatário. Esse anúncio investe mais ainda no processo de triagem na medida em que seleciona no conjunto dos possíveis enunciatários um tipo específico como consumidor daquele produto-corpo ("p/ homens acima de 37 anos"). Vejamos outro exemplo:

BRUNA, XXXXXXXX. Casada, morena, linda de rosto e corpo, p/ eles e elas.

\footnotetext{
7 Agradeço ao Prof. Dr. José Américo Bezerra Saraiva, coordenador do Grupo de Estudos Semióticos da Universidade Federal do Ceará (SEMIOCE), pelas valiosas contribuições nas análises dos exemplos. 
O texto acima, em termos enunciativos, muito se assemelha ao anterior, por ser igualmente marcado por uma debreagem enunciva actancial (Bruna), que também produz efeitos de objetividade e distanciamento no enunciado. Há, no entanto, diferenças dignas de nota entre os dois anúncios. De início, destacamos o fato de que, no primeiro, a adesão do enunciatário se realiza por meio da triagem, enquanto no segundo prevalece o regime de mistura ("p/eles e elas"). Senão vejamos: no primeiro anúncio, o objeto-corpo é apresentado pela idade e pelo recorte de suas medidas físicas (altura e peso), o que parece adensar semanticamente a figura do corpo no enunciado, reforçando o efeito de objetividade. No segundo anúncio, por seu turno, o corpo se apresenta por meio de adjetivações (casada, morena, linda de rosto e de corpo) que, de alguma maneira, relativizam a objetividade da cena descritiva do corpo, principalmente pela valoração de claro teor enunciativo promovida pelo adjetivo "linda".

Um dos fatores responsáveis por essa variação de sentido é a "iconização", da qual nos falam Greimas e Courtés (2008, p. 251): "última etapa da figurativização do discurso em que as figuras já constituídas são dotadas de investimentos particularizantes, suscetíveis de produzir a ilusão referencial”. No primeiro anúncio, o acentuado efeito iconicizante pode ser atribuído à mensuração presente na descrição do corpo-mercadoria. No segundo, ao contrário do primeiro, os adjetivos "casada" e "morena" aparecem investidos de força persuasiva pelo fato de serem figuras culturalmente axiologizadas pelo universo do "fetiche sexual" ("casada" remete à proibição e mistério e "morena", à sensualidade, por exemplo).

Por conta disso, parece haver, do ponto de vista tensivo, uma aposta na diminuição da extensidade e em um aumento gradual da intensidade. Com efeito, as predicações "casada, morena, linda de rosto e corpo" penetram no campo discursivo com graus de presença distintos daquelas do exemplo anterior (31 anos, 1,65m, $63 \mathrm{~kg}, \mathrm{p} /$ homens acima de 37 anos), afetando o sujeito muito mais pela sua qualidade sensível do que pelo seu caráter inteligível. Dito isto, passemos para o anúncio abaixo:

Luana, Se eu não for bonita e não fizer tudo, você não paga. Sou loira e gostosa. Fone XXXXXXXX.

Ao contrário dos anúncios anteriores, neste, temos duas debreagens enunciativas actoriais (eu, sou), em que a instância da enunciação se projeta no enunciado, produzindo, assim, efeitos de aproximação e subjetividade. Notemos, porém, a ocorrência de uma debreagem enunciva actorial (Luana), à semelhança dos anúncios anteriores. Trata-se de uma estratégia recorrente em anúncios publicitários para captar a atenção dos consumidores: apresentar inicialmente o produto.

Um ponto merece destaque. Nos anúncios de sexo, a eficácia das debreagens e embreagens como estratégias de persuasão repousa, em última instância, naquilo que Greimas (1983) denominou de "contrato veridictório", ou seja, "nas condições de confiança que determinam o compartilhamento das crenças, em perpétuo ajuste entre os sujeitos, no interior do discurso" (BERTRAND, 2003, p. 243).

Tomando como base a divisão da fidúcia em uma relação de crença (entre sujeito e objeto) e de confiança (entre sujeitos), conforme é apresentada por Fontanille e Zilberberg (2001), percebemos que, em nossos exemplos, as debreagens enuncivas procuram reforçar a crença do sujeito no objeto, enquanto as debreagens enunciativas tentam estabelecer a crença no objeto pela relação de confiança entre sujeitos. 
Vejamos como esse contrato fiduciário intersubjetivo se estabelece como estratégia de persuasão no anúncio em tela: o enunciador projetado em primeira pessoa no discurso confia no fazer interpretativo do enunciatário para sancionar positivamente sua performance sexual. Para isso, convoca para o enunciado um programa narrativo em forma de estrutura implicativa do tipo "se... então" ("se eu não for bonita e não fizer tudo, você não paga"), no qual o enunciador supostamente põe à prova sua competência, seu saber e seu poder-fazer, como mais uma estratégia de manipulação, cujo fito é, num primeiro momento, criar um estado de alma no enunciatário: a curiosidade. Uma vez curioso, o enunciatário vai querer e/ou dever entrar em conjunção com o corpo-objeto-de-consumo. Cabe notar que o próprio enunciatário é convocado para ocupar a posição de sancionador no programa narrativo em que o anunciador é o sujeito performático.

Um adendo: a expressão "e não fizer tudo" lança o enunciatário para o universo apenas da possibilidade; ou seja, sua adesão ao indefinido "tudo" (o que seria esse "tudo"?) não garante a competência (saber) nem a performance (fazer) do sujeito enunciante. Isso nos faz lembrar dos tipos de "fazeres" propostos por Silva et al. (1998, p. 24), quando os relacionam à veridicção do discurso:

O fazer verdictório define-se como a inscrição, pelo enunciador, de marcas que fazem o enunciado se deixar ler como verdadeiro/falso/mentiroso/ secreto. $\mathrm{O}$ fazer epistêmico constitui a ação do enunciatário de interpretar o teor veridictório do enunciado; para isso ele parte de atitudes epistêmicas coletivas $[\ldots]$. . No fazer fiduciário, o enunciatário confia ou espera mais do que o fazer epistêmico autoriza; trata-se de uma adesão efetiva/afetiva.

Em relação à segunda debreagem enunciativa actorial (“Sou loira e gostosa”), podemos considerá-la outra estratégia de manipulação, pela qual o enunciador procura estabelecer a relação fiduciária da crença no objeto-corpo, a fim de reforçar a força argumentativa do enunciado implicativo. Convém ressaltar, no entanto, que o efeito de subjetividade produzido pela debreagem em primeira pessoa faz prevalecer o acordo de confiança entre sujeitos, mais do que a crença depositada no objeto-corpo.

Outro aspecto que merece destaque é a escolha dos adjetivos pelos quais o enunciador se enuncia (bonita, loira e gostosa), haja vista serem elementos do enunciado que promovem a valorização do corpo-produto no universo dos serviços de sexo.

Analisemos um último exemplo:

Júlia, R\$ 50. Morena linda, 1.70m, 105 de bumbum, adoro por trás. Fone: XXXXXX.

O texto acima começa com uma debreagem enunciva actancial que objetiva a imagem do corpo pela dimensão do inteligível, da extensidade. Um aspecto que chama a atenção é a disposição das figuras que compõem a imagem desse corpo enunciado. Esse arranjo figurativo cria uma perspectiva de observação na qual vemos, à maneira das películas cinematográficas, um enquadramento do corpo, que vai sendo apresentado em tomadas progressivas, condicionando, dessa forma, o olhar do observador: inicialmente, sob um plano geral ("morena linda"), em seguida, recortando-o em plano americano ("1,70m, 105 de bumbum").

O fenômeno continua com a operação enunciativa de embreagem, que vem logo a seguir: "adoro por trás". Esta dupla embreagem (actancial e espacial) tanto neutraliza a Disponível em: http://seer.fclar.unesp.br/casa 
objetividade produzida pelo discurso em terceira pessoa em favor da subjetividade da primeira pessoa, como subverte o espaço enunciativo, produzindo um poderoso efeito de aproximação: uma espécie de close up, que focaliza um ponto do corpo (o bumbum 105), direcionando o olhar do observador para ele, o "bumbum".

Com isso, parece haver a criação de um duplo simulacro: o do corpo como figura objetiva e o do corpo como efeito das breagens. Se o primeiro põe o enunciatário como expectador diante da imagem do corpo, o segundo o coloca dentro dessa imagem, ou seja, fálo crer que penetra esse espaço sensível. Em termos tensivos, a focalização em uma parte específica do corpo, no caso o "bumbum 105", faz que o simulacro do corpo, antes extenso, se torne intenso, uma vez que a dupla debreagem concentra as posições de observação do enunciador/observador/enunciatário em um mesmo ponto tônico. Cria-se, por conseguinte, uma tensão entre o que antes era da ordem do inteligível e o que agora se incorpora à dimensão sensível; e não seria exagero admitir que, junto a esse simulacro do corpo, emerge o simulacro do ato sexual.

Para finalizar, Bertrand (2003, p. 260) parece ter razão quando nos diz que "o texto é uma verdadeira fábula da proprioceptividade, sugerindo-nos seu esquema", na medida em que, por seu intermédio, "o sujeito que vê e sente descobre seu espaço, e se descobre por meio dele".

\section{Conclusão}

Escolher o que mostrar de um objeto significa já "deixar escapar" algo, o que evidencia a imperfeição do ato perceptivo. Tal fato somente confirma uma relação tensiva entre sujeito e objeto que tem lugar no ato enunciativo. Importa, portanto, não somente o que se mostra, mas também como se mostra.

É esta a principal razão pela qual o corpo sofre suas metamorfoses nos textos aqui analisados. Os simulacros do corpo, resultantes tanto dos modos de organização das figuras do plano discursivo como dos mecanismos breantes da enunciação, intentam propositadamente fazer o leitor-consumidor esquecer, de alguma maneira, que está diante de simulacros. Com isso, o discurso o põe ilusoriamente em contato direto com o "objeto-corpo" que essas imagens tentam aproximadamente representar.

Com efeito, o "contágio", do qual nos fala Landowski (1996, p. 39), é precisamente isto: um tipo de relação intersomática (corpo a corpo) que se sobrepõe à relação intersubjetiva (face a face), cujo propósito é gerar um efeito de presença, em que "o sentido é sentido". Ocorre, assim, uma espécie de "gozo estésico", uma simulação da presença sensível de um corpo "real" ou de uma intimidade com um sujeito referencial.

O valor heurístico das operações enunciativas em um tipo de publicidade tão particular, como são os anúncios classificados de serviço de sexo, nisto reside: produzir a "ilusão de verdade" pela qual o sujeito da enunciação, sincretizado no par enunciador/enunciatário, reifica o corpo enunciado, criando, dessa maneira, uma espécie de voyeurismo, em que o leitor/consumidor é sensibilizado e "co-movido" pelas armadilhas do sentido. Daí surgir diante dele a imagem de um corpo já acabado, mas cuja leitura socializada pode deformá-la para atribuir-lhe novas significações.

Assim consideradas, essas operações permitem pressentir não somente a emergência do sentido pela percepção, mas também sua estabilização figurativa e posterior axiologização em um sistema de valores, em uma configuração discursiva.

Após tudo o que foi dito, interrogamos se somos nós que tornamos o outro "presente" ou seria a própria presença do outro que nos invade com uma força oculta. Valéry 
(2003, p. 125) talvez assim respondesse: "As coisas nos olham. O mundo visível é um excitante perpétuo: tudo desperta ou alimenta o instinto de se apropriar da figura ou do modelado da coisa que o olhar constrói".

\section{Referências bibliográficas}

BERTRAND, D. Caminhos da semiótica literária. Bauru/SP: EDUSC, 2003.

DUARTE, E. B. Propõem-se ... contatos imediatos: a construção da imagem corporal nos anúncios classificados. In: Assis Silva, I. (Org.), Corpo e Sentido: a escuta do sensível. São Paulo: Editora da UNESP, 1996.

FIORIN, J. L. As astúcias da enunciação. As categorias de pessoa, espaço e tempo. 1. ed. São Paulo: Ática, 2002.

FONTANILLE, J. Semiótica do Discurso. Trad. Jean Cristtus Portela São Paulo: Contexto, 2007.

FONTANILLE, J. \& ZILBERBERG, C. Tensão e significação. São Paulo: Humanitas, 2001.

GREIMAS, A. J. Du sens II. Essais sémiotiques. Paris: Éditions du Seuil, 1983. 2002.

Da Imperfeição. Tradução: Ana Claudia de Oliveira. São Paulo: Hacker Editores,

GREIMAS, A. J. \& COURTÉS, J. Sémiotique. Dictionnaire raisonné de la théorie du langage, Paris: Hachette, 1979.

Dicionário de Semiótica. Tradução de Alceu. Dimas Lima et alii. São Paulo:

Contexto, 2008. 1986.

Sémiotique. Dictionnaire raisonné de la théorie du langage, tome 2. Paris: Hachette,

LANDOWSKI, E. Viagem às nascentes do sentido. In: Assis Silva, I. (Org.), Corpo e Sentido: a escuta do sensível. São Paulo: Editora da UNESP, 1996.

LEITE, R. L. \& SARAIVA, J. A. B. O Corpo e o observador na discursivização. Acta Semiótica et Linguística, v. 14, p. 139-154, 2009.

MERLEAU - PONTY, M. Fenomenologia da Percepção. 2 ed. São Paulo: Martins Fontes, 1999.

SARAIVA. J. A. B. Pessoal do Ceará: o percurso de uma identidade e a identidade de um percurso. Tese de Doutorado. Programa de Pós-Graduação em Linguística, Universidade Federal do Ceará, Fortaleza, 2008.

SILVA, I. A. Figurativização e metamorfose: o mito de Narciso. São Paulo: Ed. UNESP, 1995.

(org.). Corpo e sentido: a escuta do sensível. São Paulo: UNESP, 1996.

SILVA, I. A. et al. O contrato fiduciário: considerações preliminares. In: Caderno de Estudos do IV colóquio do Centro de Pesquisas Sociossemióticas. v.4, p. 9-25, São Paulo, PUC, 1998. 
CASA, Vol.9 n.1, julho de 2011

TATIT, L. Musicando a semiótica. São Paulo: Annablume, 2007.

VALÉRY, P. Degas Dança Desenho. Trad. Christina Murachco e Célia Euvaldo. São Paulo: Cosac \& Naify, 2003.

ZILBERBERG, C. Síntese da gramática tensiva. Significação - Revista Brasileira de Semiótica, n. 25, p. 163-204. São Paulo: Annablume, 2006. 